\title{
Responses to the commentaries by Jean-Yves Rochex, Jean-Charles Chabanne and Andrée Tiberghien
}

Neil Mercer

\section{OpenEdition}

\section{Journals}

Electronic version

URL: http://journals.openedition.org/educationdidactique/2526

DOI: 10.4000/educationdidactique.2526

ISSN: 2111-4838

Publisher

Presses universitaires de Rennes

\section{Printed version}

Date of publication: 8 July 2016

Number of pages: $57-61$

ISBN: 9782753551787

ISSN: 1956-3485

Electronic reference

Neil Mercer, «Responses to the commentaries by Jean-Yves Rochex, Jean-Charles Chabanne and Andrée Tiberghien », Éducation et didactique [Online], 10-2 | 2016, Online since 08 July 2018, connection on 06 May 2019. URL : http://journals.openedition.org/educationdidactique/2526 ; DOI : 10.4000/educationdidactique. 2526 


\section{RESPONSES TO THE COMMENTARIES BY JEAN-YVES ROCHEX, JEAN-CHARLES CHABANNE AND ANDRÉE TIBERGHIEN}

Neil Mercer

\section{Remerciements}

I would like to thank the three eminent scholars for their very thoughtful, and though-provoking, comments on my paper (and the seminar presentation which generated it). I will deal with each commentary in turn. 
Neil Mercer

\section{JEAN-YVES ROCHEX}

Jean-Yves Rochex explains that he, like me, believes that the current dominant conception of the 'social brain' still embodies an individualistic perspective on the nature of human cognition. However, unlike me, he is unconvinced that the 'social brain' concept can or should be modified to take account of this failing. I agree when he says that "there is in the social brain hypothesis a danger to confuse two different topics: the brain's structure and modes of functioning as condition of possibility for our social (and cultural) behaviours, and as an explication for these behaviours"; and I am also just as wary of neuroscientific reductionism. But I am also reluctant to contribute to building strong divisions between his (and my) position and those of the less reductionist and more open-minded neuroscientists. I think the best way forward would be to reach a welljustified position which takes account of relevant evidence and theory from both the biological and social sciences. We do not have to accept that human behaviour is entirely shaped by biology to accept that, as an organ of human body, the brain has evolved to enable forms of learning, communication and cooperative problem solving which other mammalian brains cannot support. It is the biological nature of that brain which allows humans to transcend the determinism of instinctive capabilities, and so allow children's cognitive development to be influenced by tensions or contradictions "between the developed cultural forms of thinking, acting and feeling in which children are involved and the primitive forms which characterize their own behavior" (Vygotski, $1931 / 2014$, as quoted by Rochex). It is for these reasons that I think the 'social brain' concept deserves to be retained. In any case, even if we are not agreed on the value of that concept as such, I take great reassurance in Rochex's comment that "I do agree with the main theses that Mercer draws from his discussion of the social brain hypothesis, namely the paramount importance of joint intellectual activity and collaboration for human development and for the human ability to more than just interact, but rather to interthink."

Moving on to consider Rochex's discussion of classroom dialogue and joint activity, I think we are in total accord. I agree entirely that many non-linguistic aspects of classroom interaction can influence the quality of collaborative learning, as can the specific tasks set and the artefacts involved, even though I have given little attention to them in my own discussion. I justify that only on the basis of maintaining a focus on the importance of the role of language, which I believe is itself often not given enough attention.

The next part of Rochex's commentary is concerned with Bernstein and Vygotsky. I am very willing to be persuaded of the need to incorporate a sociological dimension into a sociocultural account of education; and Bernstein is probably the sociologist who has given most attention to the relationship between language, cognition, culture and education. (I had some personal correspondence with Bernstein in the 1980s about the normative concept of classroom 'ground rules' for classroom talk.) As Rochex explains, Bernstein's work certainly brings out the heterogeneity of culture, and its potential influence on children's educational experience, in a way that Vygotsky's does not. Rochex's own work, as summarised in his commentary, elaborates this issue well. Moreover, this elaboration makes useful connections with the concept of self-regulation, which is now being given considerable attention by Vygotskian developmental psychologists (Dignath, Buettner \& Langfeldt, 2008). As Rochex argues, the educational implications of this analysis are that there is a need to raise both pupils' and teachers' awareness of aspects of classroom communication which normally remain implicit.

In conclusion, Rochex argues for a distinction between three relevant meanings of 'social', which I read as moving from interactional, through normative-cultural to societal phenomena. I agree completely that the third meaning, or third level, is as important for understanding education as the other two, and that (despite the influence of Marxist theory) it is left vague in Vygotsky's work. But whether or not that third level is incompatible with an improved conception of the social brain, I remain unsure.

\section{JeAn-Charles Chabanne}

Jean-Charles Chabanne explains that his comments are shaped by intention of showing how the ideas I have discussed in my article relate to French academic traditions (about which I shamefully admit do not know as much as I should). One of the first researchers he mentions in this 
respect is the psychologist Henri Wallon, whose work is only familiar to me through his proposal that children's cognitive development is influenced by the dialectic relationship between emotion and intelligence. Being influenced by Marxist ideas about the relationship between social/cultural factors and individual development, it is perhaps not surprising that Wallon, like Vygotsky, gave the acquisition and use of language a prominent role in his developmental model. As such, I can see that Chabanne is right in perceiving compatibility between Wallon's work and the concept of the 'social brain' (in its modified form).

Similarly, Chabanne asks whether links can be made with the work of Jerome Bruner. Bruner's conception of the child's cognitive development, and the role of other people in it, is certainly a sociocultural formulation. The concept of 'scaffolding', developed by Bruner, Wood and Ross (1976), is certainly closely related to Vygotsky's concept of the Zone of Proximal Development. But, like Chabanne, I see no criticism in Bruner's work of the Chomskyan/Pinker conception of language as a relatively autonomous component of human cognition. Regarding the relationship between Piaget and Vygotsky, I was very influenced by hearing Bruner (speaking at a conference in Geneva in 1972) exhorting us not to dwell too much on the disparities between their theories, but instead to celebrate the fact that we have from them two wonderful narrative accounts of children's cognitive development to guide our own understanding.

Turning to the concept of 'metacognition', I agree with Chabanne that educational researchers like us have a duty to offer teachers clear and practically useful explanations of this concept (not least because the development of metacognitive and selfregulatory abilities appears to be linked to academic achievement: Dignath, Buettner \& Langfeldt, 2008). Likewise, in his discussion of aspects of evolutionary psychology, I agree that we need to know more about how, and to what extent, collective thinking (interthinking) is a vital influence on the development of individual thinking. Chabanne then goes on to make very interesting links between the development of 'theory of mind' capacity and the interpretation of art.

I am indebted to Chabanne for identifying the ways that work in the French tradition of language sciences has explored the relationship between language and thought; and I will certainly reflect on his interesting question about the relevance of research in cognitive linguistics to the development of the social brain hypothesis. Cognitive linguistics represents an approach which is very different from that of Chomskyan linguistics; some linguists, like Evans (2012) even consider the two 'diametrically opposed'. And, as Evans goes on to explain, cognitive linguists are committed to providing a characterization of language that accords with what is known about the mind and brain from other disciplines (and not just a model that gives priority to the elegance and internal consistency of a formal linguistic model). As such, cognitive linguistics should be much more open to influence by the interdisciplinary research that I discuss in my article than more formalistic, 'autonomous' linguistic approaches. But although some cognitive linguists have espoused a 'social turn' in their theorizing (Harder, 2009; Sinha, 2009), I am not aware of any consideration of how that approach relates to Vygotskian, sociocultural approaches to language, cognitive development and education.

Regarding the relationship between my discussion of the social brain and research in sociological and anthropological fields; I agree with Chabanne that the interest in knowledge as a collective entity and its role in enabling language use shown by ethnomethodologists and sociolinguists such as Garfinkel and Gee would seem compatible with the kind of approach to language and thinking I am trying to develop. I have certainly drawn quite heavily on those research traditions in developing my own methodology for analysing discourse. However, I know that some ethnomethodologists and discursive psychologists are resistant to the idea that we can ever study 'thinking' at all, as their empiricist philosophy is incompatible with the inference of thought processes from behaviour (Edwards, 1997; Wooffitt, 2009). But it may be that this does not apply to the French researchers such as Bernié and Mottiez-Lopez cited by Chabanne. With regard to Chabanne's questions about the relevance of sociology of education: I hope my early responses to Rochex's comments about the relevance of the work of Bernstein go some way to providing an answer. I am still a novice student of the French research tradition of sociodidactique, and so I leave it to others who are better informed to make connections there.

I have nothing but agreement with Chabanne's discussion of the way our research into classroom 
language as "talking-to-produce-talking-to-learn" should be made useful to teachers. And I thank him for drawing my attention to the wealth of relevant work in France on language across the curriculum. I am currently engaged in an attempt (with others) to relate the study of language use and language development in school to the ways language is used to get things done in other workplaces in wider society (see [http://www.hughes.cam.ac.uk/ academic-life/study-centres/oracy/)] .

I turn next to Chabanne's 'semiotic problemization' of the concept of language. I can only agree that I, like many researchers into language in use, tend to give little direct attention to non-verbal aspects of communication in the classroom, and to the use of artifacts in the process of teaching-and-learning. My strong expectation is that children's non-verbal sensitivities and skills could be developed through activity and discussion guided by a teacher, though I do not know of research on such matters. In answer to the direct question posed: Yes, I do think those multimodal aspects of classroom life (and social life generally) should be taken into account in developing a more sociocultural conception of the social brain. But I think that any one researcher cannot attempt to deal with all of that: it should be an enterprise for interdisciplinary endeavour and interthinking. And in conclusion, I take great reassurance that Chabanne agree with me that, for the sake of improving education as well as for the development of our scientific understanding, we should try to overcome the influence of an inherently individualistic conception of human cognition and its development.

\section{ANDRÉE TIBERGHIEN}

Andrée Tiberghien offers comments on three main themes related to the content of my paper, which I paraphrase as (a) the tool of language, (b) the shift of research focus from individual to collective, and (c) the implications of that shift for how we characterize classroom education. And then, in conclusion, she offers some queries and comments about educational theory.

On the first theme, Tiberghien makes the nature and functions of the specialized language genre of a subject like science clearer than I have in my paper. As she says, one important way a teacher can help students' learning of physics is help them move from using technical language in a merely normative way (to conform to the culturally-based expectations about how phenomena should be described in a science lesson) into a more profoundly different kind of functional usage (whereby they use the affordances of the language of science to describe phenomena in scientific, rather than everyday, ways).

My discussion of the Vygotskian reciprocal link between the intermental and the intramental leads her emphasise the importance of recognising the relationship between the talk between a teacher and students and talk amongst students working together. I agree completely with this emphasis. As I often say to students of education, the two kinds of talk should be considered metaphorically as two sides of the same coin. And as Tiberghien says, the relationship between them evolves through time; it is a socio-historical relationship.

Regarding the shift in research perspective from the individual to the collective, Tiberghien argues - rightly, in my view - that some concepts which are commonly used to characterise learning as social - notably 'communities of practice' - are still inherently individualistic because they focus on individual agency and personal identity rather than on the evolution of groups or communities as collective, knowledge-building entities.

Tiberghien next discusses the theoretical implications this shift in perspective for how we characterise classrooms, relating it first to my early work with Derek Edwards. She then her draws upon own more recent work and that of Sensevy on joint actions in didactics, which in turn draws on the Wittgensteinian notion of a language game. As she puts it "characterising the rules of the game and their origin is a way to study the social structure of the classroom." This relates to the notion of 'educational ground rules' Edwards and I employed to describe the implicit, normative basis of classroom life; and which (as I mentioned in response to Rochex) was also used in a similar way by Bernstein. If I have understood matters correctly, Tiberghien suggests that one potentially problematic feature of the common knowledge which teachers and students must share if the educational process is to be successful are the conditions of the 'didactic contract' which both take for granted when they engage in classroom interactions. For example, a student and a teacher may have different conceptions of the terms of this contract and also of the ground rules involved in 
putting it into action. Research which took account of these potentially different interpretations could help to relate, and reconcile, perspectives on education as both an individual and collective enterprise. I agree that it could be particularly useful if such research include a temporal dimension, in which classroom life was studied at different scales of time.

\section{CONCLUSION}

Overall, then, I am very grateful to all three researchers for taking my ideas seriously, and providing such thoughtful commentaries. I hope we - and our readers - can see our collection of texts as a productive example of the very process of interthinking with which we are concerned: we have engaged in critical, supportive, collaborative, exploratory discussion in the pursuit of the common goal of understanding the communicative process of classroom education.

\section{REFERENCES}

Dignath, C., Buettner, G., \& Langfeldt, H.-P. (2008). How can primary school students learn self-regulated learning strategies most effectively? A meta-analysis of self-regulation training programmes. Educational Research Review, 3, 101-129.

Evans, V. (2012). Review of Cognitive Linguistics. WIREs Cognitive Science. Doi: 10.1002/wcs.1163. New York: John Wiley and Son.

Harder, P. (2009) Meaning in Mind and Society. Berlin: Mouton.

Sinha, C. (2009). Language as a biocultural niche and social institution. In: V. Evans \& S. Pourcel (Eds.) New directions in cognitive linguistics. Amsterdam: John Benjamins, pp. 289-310.

Edwards, D. (1997). Discourse and Cognition. London: Sage.

Wood, D., Bruner, J., \& Ross, G. (1976). The role of tutoring in problem-solving. Journal of Child Psychology and Child Psychiatry, 17, 89-100.

Wooffitt, R. (2005). Conversation Analysis and Discourse Analysis: A Comparative and Critical Introduction. London: Sage Publications. 